\title{
Screening and Characterization of Oleaginous Fungi from Irish Soil for Growth under Low Carbon Substrates
}

\author{
Iniya Kumar Muniraj ${ }^{1 *}$, Liwen Xiao ${ }^{2}$, Zhenhu $\mathrm{Hu}^{3}$ and Xinmin Zhan ${ }^{1}$ \\ ${ }^{1}$ Civil Engineering, College of Engineering and Informatics, National University of Ireland \\ Galway, Galway, Ireland \\ ${ }^{2}$ Department of Civil, Structural and Environmental Engineering, Trinity College Dublin, \\ Dublin, Ireland \\ ${ }^{3}$ School of Civil Engineering, Hefei University of Technology, Hefei, People's Republic of China \\ *Corresponding author
}

\begin{tabular}{|c|c|}
\hline & A B S T R A C T \\
\hline $\begin{array}{l}\text { Ke y w o r d s } \\
\text { Oleaginous } \\
\text { microorganims, } \\
\text { Diversity, Enzyme } \\
\text { secreting capability, } \\
\text { Single cell oil, } \\
\text { Biodiesel } \\
\text { production. }\end{array}$ & \multirow{3}{*}{$\begin{array}{l}\text { In this study oleaginous microorganisms were screened from Irish soils and are } \\
\text { characterized under low cost carbon substrates for economic lipid production. Total of } 247 \\
\text { fungi cultures were isolated from soil samples collected from various parts Ireland. } \\
\text { Oleaginous } 50 \text { isolates were screened on glucose and starch at } 3 \% \text { concentrations } \\
\text { respectively. The maximum lipid content in biomass was observed in the isolate I16-3, up } \\
\text { to } 44.3 \% \text {. The lipid yield with respect to glucose consumed, } \mathrm{Y}_{\mathrm{L} / \mathrm{C}} \text { (g lipids/g glucose } \\
\text { consumed), } \mathrm{Y}_{\mathrm{L} / \mathrm{C}} \text { values were in the range of } 4.7-14.0 \mathrm{~g} \text { lipids } / 100 \mathrm{~g} \text { of glucose consumed. } \\
\text { The lipid content in biomass ranged from } 19 \% \text { to } 39 \% \text {; the maximum lipid content }(39 \%) \\
\text { was observed in the same isolate I16-3. Interestingly, the isolate had a slightly higher lipid } \\
\text { yield ( } 4.3 \mathrm{~g} / \mathrm{L}) \text { when grown on } 3 \% \text { starch medium than } 3 \% \text { glucose medium }(4.1 \mathrm{~g} / \mathrm{L} \text { ). In } \\
\text { addition to that } 19 \text { isolates were positive (+ve) for amylase secretion with a production of } \\
34 \mathrm{U} / \mathrm{mL} \text {. Trichoderma sp., Penicillium sp., Aspergillus sp., Mortierella sp., Zygomycetes } \\
\text { sp., Acremonium sp. and Umbiliopsis sp are the seven genera in which the oleaginous } \\
\text { fungi were grouped. }\end{array}$} \\
\hline Article Info & \\
\hline $\begin{array}{l}\text { Accepted: } \\
\text { 07 October } 2017 \\
\text { Available Online: } \\
\text { 10 December } 2017\end{array}$ & \\
\hline
\end{tabular}

\section{Introduction}

In recent days microbial lipids are considered as one of the potential alternative to Biodiesel production. In nature several microorganisms when grown under nutrient stress conditions (High $\mathrm{C}$ : $\mathrm{N}$ ) ratio including bacteria, fungi, yeast and algae capable of producing microbial oils (1-6). Utilization of low cost materials for production of lipids is major concern for commercialization. The number of oleaginous microorganisms currently in use for energy production is limited; for example, of the 600 yeasts only $25 \%$ are known to produce lipids and among 60,000 fungal species less than $50 \%$ are known to accumulate lipids (7). Although the numbers seem large, the number of oleaginous microorganisms in use is limited, since the microbial lipid production research and application until now is focused on production of special lipids rich in poly unsaturated fatty acids (such as gamma linolenic acid and arachidonic acid) (1, 8-12). Oleaginous fungi used for these special lipids production are mainly cultures belonging to 
the Mucorales order (13). Such mucaraceous oleaginous fungi for biodiesel production has a limited scope as their microbial oils would contain a high linolenic acid content, which does not satisfy the European standards (EN14214 and 14213) for biodiesel production (14). Hence search for newer organisms with potential oil yielding capacity becomes essential. While searching for hyper oleaginous microbes, their environment in which these organisms grow and produce oils, their adaptability are to be considered.

Feedstocks for the second generation biodiesel include biomass, agricultural and forestry residues, and biowastes (15). In order to utilize these residues for lipid production, oleaginous microorganisms should have respective enzymes to breakdown complex organic molecules, like cellulose, starch, etc. Otherwise external enzymes need to be added, thus increasing the lipid production cost. It is reported that when oleaginous fungi Mortierellais abelliana ATHUM 2935 and Cunninghamella echinulata ATHUM 4411were grown on renewable carbon sources (starch, pectin and lactose) their lipid yields were greatly influenced by secreted enzymes (amylase and polygalucturonase) (16).

Hence, it is of particular interest to isolate more and more oleaginous microorganisms with the capability to secrete enzymes(5). Oleaginous yeasts with xylose assimilating capability for utilizing ligno-cellulosic wastes for the second generation biodiesel production is attempted (17). Furthermore, the oleaginous microorganisms must be safe to human beings, local ecology and local environment. Diversity of oleaginous microorganism form Irish soils is explored and their lipid production capability was studied, in addition lipid production on complex carbon sources and their respective fatty acid content is also described. Finally biodiesel properties of lipids produced by oleaginous microorganisms were evaluated and their feasibility was reported in this chapter.

\section{Materials and Methods}

\section{Soil sample collection}

Fifty undisturbed soil samples were collected from various locations in western Ireland and used for isolation of oleaginous fungi. Upper layer $(5-15 \mathrm{~cm})$ undisturbed soils were collected with sterile polyethylene bags, brought to the laboratory and used immediately for isolation studies.

\section{Isolation of oleaginous fungi}

Fungi were isolated from soil samples by means of the serial dilution and plating method. Ten gram of each soil sample was suspended in $90 \mathrm{~mL}$ of sterile distilled water added in $250 \mathrm{~mL}$ conical flasks; the flasks were shaken vigorously for five minutes. The suspensions were serially diluted up to one thousand folds. One mL of the one thousand dilution aliquot was transferred aseptically in a Class II biosafety cabinet (Fisher Scientific, Ireland) onto sterile Petri dishes and then 10$15 \mathrm{~mL}$ of molten PDA medium was poured into the Petri dishes. Filter sterilized Kanamycin (35ppm) was added into the sterilized PDA medium before plating. The plates were incubated at $30^{\circ} \mathrm{C}$ for 5 days. Single fungal colonies were isolated and transferred repeatedly to new plates until pure cultures were obtained, which were maintained in PDA slants and stored at $4{ }^{\circ} \mathrm{C}$.

\section{Screening for lipid production}

Cultures with a good mycelial morphology were selected for screening. Mycelium was taken from disks using a cork borer from the actively growing area and was pre-cultured in the Yeast Extract Malt Extract (YEME) broth for 2 days. The composition of the medium 
was $(\mathrm{g} / \mathrm{L})$ : glucose, 10; peptone, 5; yeast extract, 3; and malt extract, 3. After two days, the mycelium was harvested, and then mycelium with a wet weight less than $10 \mathrm{~g}$ was transferred to $10 \mathrm{~mL}$ sterile plastic tubes (Fisher scientific, Ireland). 5-8 sterile glass beads (5 mm diameter) were added and the mycelium was homogenised using vortex for two min. $0.8 \mathrm{~mL}$ of the homogenised mycelium was then transferred into $250 \mathrm{~mL}$ conical flasks containing $50 \mathrm{~mL}$ of the lipid producing medium, which consisted of $(\mathrm{g} / \mathrm{L})$ : glucose, 30; yeast extract, 1.5; $\mathrm{KH}_{2} \mathrm{PO}_{4}, 7$; $\mathrm{Na}_{2} \mathrm{HPO}_{4}, \quad 5 ; \quad \mathrm{MgSO}_{4}, \quad 1.5 ; \mathrm{FeCl}_{3}, 0.08$; $\mathrm{ZnSO}_{4}, 0.01 ; \mathrm{CaCl}_{2}, 0.1 ; \mathrm{MnSO}_{4}, 0.1 ; \mathrm{CuSO}_{4}$, 0.1 ; and $\mathrm{CO}\left(\mathrm{NH}_{3}\right)_{2}, 0.1$. The medium had a $\mathrm{pH}$ value of 5.5. Glucose in this medium was replaced with $30 \mathrm{~g} / \mathrm{L}$ of starch while studying the capability of isolated oleaginous fungi in lipid production with starch as the carbon source.

Then, the cultures were incubated in an orbital shaker incubator (Fisher Scientific, Ireland) at a shaking speed of $160 \mathrm{rpm}$ and an incubation temperature of $30 \pm 1^{\circ} \mathrm{C}$. Flasks were periodically removed from the shaker incubator and the samples were filtered using $0.09 \mathrm{~mm}$ stainless steel sieve (Starsdet, Germany). Filtrates were centrifuged again at $5000 \mathrm{rpm}$ for $5 \mathrm{~min}$ and used to analyze glucose, starch and amylase. The biomass was used for extraction of lipids.

\section{Analytical methods}

\section{Residual glucose analysis}

Remaining glucose in the culturing supernatant was analyzed using the DNS method (Miller, 1959). $1 \mathrm{~mL}$ of the supernatant samples was added into $15 \mathrm{~mL}$ glass tubes and the liquid volume in the tubes was equalized to $3 \mathrm{~mL}$ by adding distilled water. The tubes were then added with $3 \mathrm{~mL}$ of DNS reagent and were placed in a water bath at $90^{\circ} \mathrm{C}$ for 5 min. $1 \mathrm{~mL}$ of $40 \%$ Rochelle salt solution (potassium sodium tartrate) was added to the tubes when the contents were still warm. After the tubes were cooled to the ambient temperature, the intensity of a dark red color was read at the wavelength of 510 nm using a spectrophotometer (Hach Lange, Ireland). $1 \mathrm{~mL}$ of distilled water was added in a $15 \mathrm{mLglasstube}$ and used as the blank sample; the procedure mentioned above was repeated. A series of glucose solutions with known glucose mass $(0-500 \mu \mathrm{g})$ were run in parallel for the purpose of calibration.

\section{Residual starch analysis}

Residual starch in the culturing supernatant was analyzed according to the phenol sulphuric acid method (Dubois et al., 1956). $0.1 \mathrm{~mL}$ of the supernatant sample was added in $15 \mathrm{~mL}$ glass tubes and the liquid volume was made up to $1 \mathrm{~mL}$ with distilled water. 1 $\mathrm{mL}$ of phenol and $5 \mathrm{~mL}$ of $96 \%$ sulphuric acid solution were added into the tubes. The contents were well mixed by inverting the tubes several times and left undisturbed for 10 min. Then, the tubes were shaken and placed in a water bath at $25-30{ }^{\circ} \mathrm{C}$ for $20 \mathrm{~min}$. The contents were cooled at ambient temperature and the colour intensity was read at the wavelength of $490 \mathrm{~nm}$ using the spectrometer. The blank sample was $1 \mathrm{~mL}$ of distilled water with the procedure mentioned above repeated. The same procedure was followed to standard glucose solutions containing $0-500 \mu \mathrm{g}$ glucose for the purpose of calibration.

\section{Screening for amylase secretion}

Preliminary screening of fungi with amylase secretion was conducted on $2 \%$ starch agar medium in plates. A disk of actively growing mycelium was placed in the centre of the plates, incubated at $30^{\circ} \mathrm{C}$ and examined after 24 - 48 h. $\alpha$-amylase producing cultures were selected by the formation of a clearance zone 
when the plates were flooded with iodine solution (1\% iodine in $2 \%$ potassium iodide, w/v). Amylase secretion of positive cultures was quantified after incubating these species with the lipid producing medium containing $3 \%$ starch for five days. The amylase activity was measured by mixing $1 \mathrm{~mL}$ of starch solution with $1 \mathrm{~mL}$ of properly diluted culturing supernatant in a tube, followed by incubation at $27{ }^{\circ} \mathrm{C}$ for $15 \mathrm{~min}$. Then $2 \mathrm{~mL}$ of DNS solution was added and the mixture was heated in a boiling water bath for $5 \mathrm{~min}$; when the tubes were still warm, $1 \mathrm{~mL}$ of potassium sodium tartrate solution was added and the tubes were cooled to ambient temperature. The liquid volume was then made up to 10 $\mathrm{mL}$ with distilled water and the colour intensity was read at the wavelength of 560 $\mathrm{nm}$ using the spectrophotometer. One unit of amylase activity (IU/mL) was defined as the number of $\mathrm{mg}$ of maltose liberated by $1 \mathrm{~mL}$ of $1 \%$ enzyme solution per 5 min (Bernfeld, 1955).

\section{Biomass analysis}

Fungal biomass was analyzed by filtering the contents in conical flasks using $0.09 \mathrm{~mm}$ stainless steel sieve (Starsdet, Germany). Filtered biomass was washed twice with distilled water and then dried at $100{ }^{\circ} \mathrm{C}$ until a constant weight.

\section{Lipid extraction}

Lipid extraction from dried biomass was performed according to the Bligh and Dyer method. $100 \mathrm{mg}$ of dry biomass was weighed accurately and added into a reacti vial (Fisher Scientific, Ireland). The lipids were extracted from the biomass using $3 \mathrm{~mL}$ of chloroform and methanol mixture $(2: 1 ; \mathrm{v} / \mathrm{v})$ overnight by shaking the tubes gently on a mini shaker (Starsdet, Ireland). Then lipids were separated by adding $1 \mathrm{~mL}$ of water followed by centrifugation (Sigma Aldrich, Ireland) at
$3000 \mathrm{rpm}$ for10 minutes. The lower liquid phase containing lipids was then transferred using Pasteur pipette; the solvents in the extracts were evaporated using dry nitrogen gas and the lipids were measured gravimetrically (Bligh and Dyer, 1959).

\section{Equations}

The lipid content in biomass, $\mathrm{Y}_{\mathrm{L} / \mathrm{X}}$, was calculated using Equation 3.1:

$Y_{L / X}=\frac{L_{\max }}{X}[$ Eq. 3.1]

Where,

$\mathrm{L}_{\max }$, maximum lipid yield, $\mathrm{g} / \mathrm{L}$; and

$\mathrm{X}$, biomass yield corresponding to the maximum lipid yield, $\mathrm{g} / \mathrm{L}$.

The amount of biomass yield with respect to the substrate consumption, $\mathrm{Y}_{\mathrm{X} / \mathrm{C}}$, is calculated using Equation. 3.2:

$Y_{X / C}=\frac{x}{\left(c_{\mathrm{i}}-C_{f}\right)}$ [Eq.3.2]

$Y_{X / C}$, biomass yield with respect to carbon substrate consumed, g biomass/g substrate;

$\mathrm{X}$, fungal biomass yield at time $\mathrm{t}, \mathrm{g} / \mathrm{L}$;

$\mathrm{C}_{\mathrm{i}}$, initial carbon substrate concentration, $\mathrm{g} / \mathrm{L}$; and

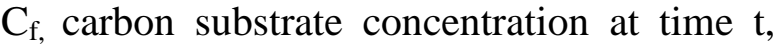
$\mathrm{g} / \mathrm{L}$.

The lipid yield with respect to carbon substrate consumption, $Y_{L / C}$, was calculated using Equation 3.3:

$Y_{L / C}=\frac{L_{\max }}{\left(c_{\mathrm{i}}-C_{f}\right)}[$ Eq. 3.3] 
Where,

$\mathrm{C}_{\mathrm{f}}$, carbon substrate concentration at time $\mathrm{t}$ corresponding to the maximum lipid yield, $\mathrm{g} / \mathrm{L}$.

\section{DNA extraction}

Three loops of oleaginous fungal cultures were scrapped from PDA plates and inoculated in YEME broth (Section 3.2.3) and incubated for $24-48 \mathrm{hrs}$ in a shaker incubator (Fisher Scientific, Ireland) at a shaking speed of $160 \mathrm{rpm}$ at $30 \pm 1^{\circ} \mathrm{C}$. Genomic DNA of the cultures was extracted using Cambio Microbial DNA Isolation Kit (CAMBIO, UK) according to the manufacturer's protocol.

\section{PCR amplification}

Polymerase chain reaction (PCR) amplification of 18s rDNA gene was carried out using a master cycler gradient thermo cycler (Eppendorf, Germany). PCR reactions were performed in $25-\mu 1$ volumes containing $1 \mu \mathrm{l}$ of DNA, $12 \mu \mathrm{l}$ of PCR master Mix (Applied Biosystems, UK), $2 \mu 1$ each forward and reverse primers and $8.0 \mu \mathrm{l}$ of PCR water (Sigma, Ireland). The forward primer was EF4 (5'-GGAAGGGRTGTATTTATTAG-3') and the reverse primer was EF3 (5'TCCTCTAAATGACCAAGTTTG-3'). The thermo cycle patterns were as follows: $94{ }^{\circ} \mathrm{C}$ for $3 \mathrm{~min}$ (one cycle); $94{ }^{\circ} \mathrm{C}$ for $1 \mathrm{~min}, 50{ }^{\circ} \mathrm{C}$ for $1 \mathrm{~min}, 72{ }^{\circ} \mathrm{C}$ for $2 \mathrm{~min}$ (40 cycles); and 72 ${ }^{\circ} \mathrm{C}$ for $10 \mathrm{~min}$ (one cycle). PCR products with a correct size were confirmed by $1 \%$ agarose gel electrophoresis.

\section{Nucleotide sequencing}

The sequencing of purified PCR products containing $1.5-1.6 \mathrm{~kb}$ of $18 \mathrm{~s}$ rDNA was carried out by means of automated sequencing (Euro Fins Biotech Pvt. Ltd.,
Germany). The sequence data generated were subjected to homology search through Basic Local Alignment Search Tool (BLAST) of National Centre for Biotechnological Information (NCBI) (www.ncbi.nlm.nih.gov/Blast). New gene sequences of isolates were submitted to the NCBI.

\section{Results and Discussion}

\section{Growth and microbial lipid production of isolates in the glucose containing medium}

Among the fifty fungal isolates screened for lipid production, 30 isolates were able to convert glucose into lipids with the lipid contents in biomass ranging from $20 \%$ to $44 \%$ within 7 days of cultivation.Therefore, these 30 isolates were designated as oleaginous. Glucose supported biomass growth (4.4 to $11.8 \mathrm{~g}$ biomass yield/L medium) and was consumed by all the 30 cultures (11.0 to $29.3 \mathrm{~g}$ glucose consumed/L medium) (Fig. 1). The maximum lipid content in biomass was observed in the isolate I16-3, up to $44.3 \%$. The lipid yield with respect to glucose consumed, $\mathrm{Y}_{\mathrm{L} / \mathrm{C}}$ (g lipids/g glucose consumed), $\mathrm{Y}_{\mathrm{L} / \mathrm{C}}$ values were in the range of 4.7 -14.0 g lipids/100 g of glucose consumed. The higher $\mathrm{Y}_{\mathrm{L} / \mathrm{C}}$ values demonstrate the higher the substrate conversion efficiency of the isolated oleaginous fungi. The isolate I16-3 had the maximum $\mathrm{Y}_{\mathrm{L} / \mathrm{C}}$ of $14.0 \mathrm{~g}$ of lipids yield per $100 \mathrm{~g}$ of glucose consumed. Eight isolates (I1A1, I1A3, I1 A5, I5-8, I8-1, I14-5, I16-3 and I18-1) had $\mathrm{Y}_{\mathrm{L} / \mathrm{C}}$ higher than $10 \mathrm{~g}$ of lipids yield per $100 \mathrm{~g}$ of glucose consumed. In the study, glucose was not completely utilized by any of the selected fungi; hence occurrence of lipid turnover was not observed. With the glucose concentration of $30 \mathrm{~g} / \mathrm{L}$ the maximum $\mathrm{Y}_{\mathrm{L} / \mathrm{C}}$ values obtained for Mortierella isabelliana and Cunninghiamella echinulata were 10.6 and $11.3 \mathrm{~g}$ lipids/100 $\mathrm{g}$ of glucose consumed, respectively(16). Our present study identified oleaginous fungi with higher 
$\mathrm{Y}_{\mathrm{L} / \mathrm{C}}$ values. The literature also reports much lower $\mathrm{Y}_{\mathrm{L} / \mathrm{C}}$ values. For example, Z. moelleri MUCLL1430 had $Y_{L / C}$ of $4.23 \mathrm{~g}$ lipids/100 g of glucose consumed, $M$. ramannia ATHUM2922 had $5.0 \mathrm{~g}$ lipids $/ 100 \mathrm{~g}$ of glucose consumed, $R$. stolonifer LGAM (9)1 had $4.5 \mathrm{~g}$ lipids/100 $\mathrm{g}$ of glucose consumed, R. stolonifer BPIL 1676 had $2.8 \mathrm{~g}$ lipids/100 g of glucose consumed, and Mucor rouxianus CBS120-08 had $1.2 \mathrm{~g}$ lipids/100 g of glucose consumed when cultivated on glucose(18).

Growth and microbial lipid production of isolates in the starch containing medium

All the selected fifty isolates were grown on the medium containing $3 \%$ starch to test their capability in lipid accumulation with starch as the carbon substrate. After 7days of incubation 19 cultures were able to accumulate lipids; interestingly all the 19 cultures were among the 30 cultures which were able to accumulate lipids in the medium containing 3\% glucose (19). Other 11 cultures did not accumulate lipids in the starch containing medium; this might be because glucose is a simple carbon source. A noticeable amount of biomass was produced $(4.8-15.0 \mathrm{~g} / \mathrm{L})$ and the maximum biomass value obtained (among the 19 cultures) in the starch containing medium was higher than in the glucose containing medium (15.0 against $11.8 \mathrm{~g} / \mathrm{L}$ ), confirming that starch is a good substrate carbon for oleaginous fungi $(16,19)$. All the 19 cultures utilized starch above 15 $\mathrm{g} / \mathrm{L}$ (Table 1). The lipid content in biomass ranged from $19 \%$ to $39 \%$; the maximum lipid content (39\%) was observed in the same isolate I16-3. Interestingly, the isolate had a slightly higher lipid yield $(4.3 \mathrm{~g} / \mathrm{L})$ when grown on 3\% starch medium than 3\% glucose medium $(4.1 \mathrm{~g} / \mathrm{L})$. Moreover, the maximum lipid yield obtained by Isolate I16-3 (4.3 g/L) is comparable with other researchers' data. For instance, 3.7 and $3.8 \mathrm{~g} / \mathrm{L}$ of lipids were produced by Mortierella isabelliana and Cunninghiamella echinulata when grown on 3\% starch (16). $3.4 \mathrm{~g} / \mathrm{L}$ microbial lipids were produced when Aspergillus oryzae cultured on $4 \%$ starch. Our isolates possessed a higher lipid yield than reported species.

Fig.1 Characterization of isolated oleaginous fungi cultured in the glucose containing medium

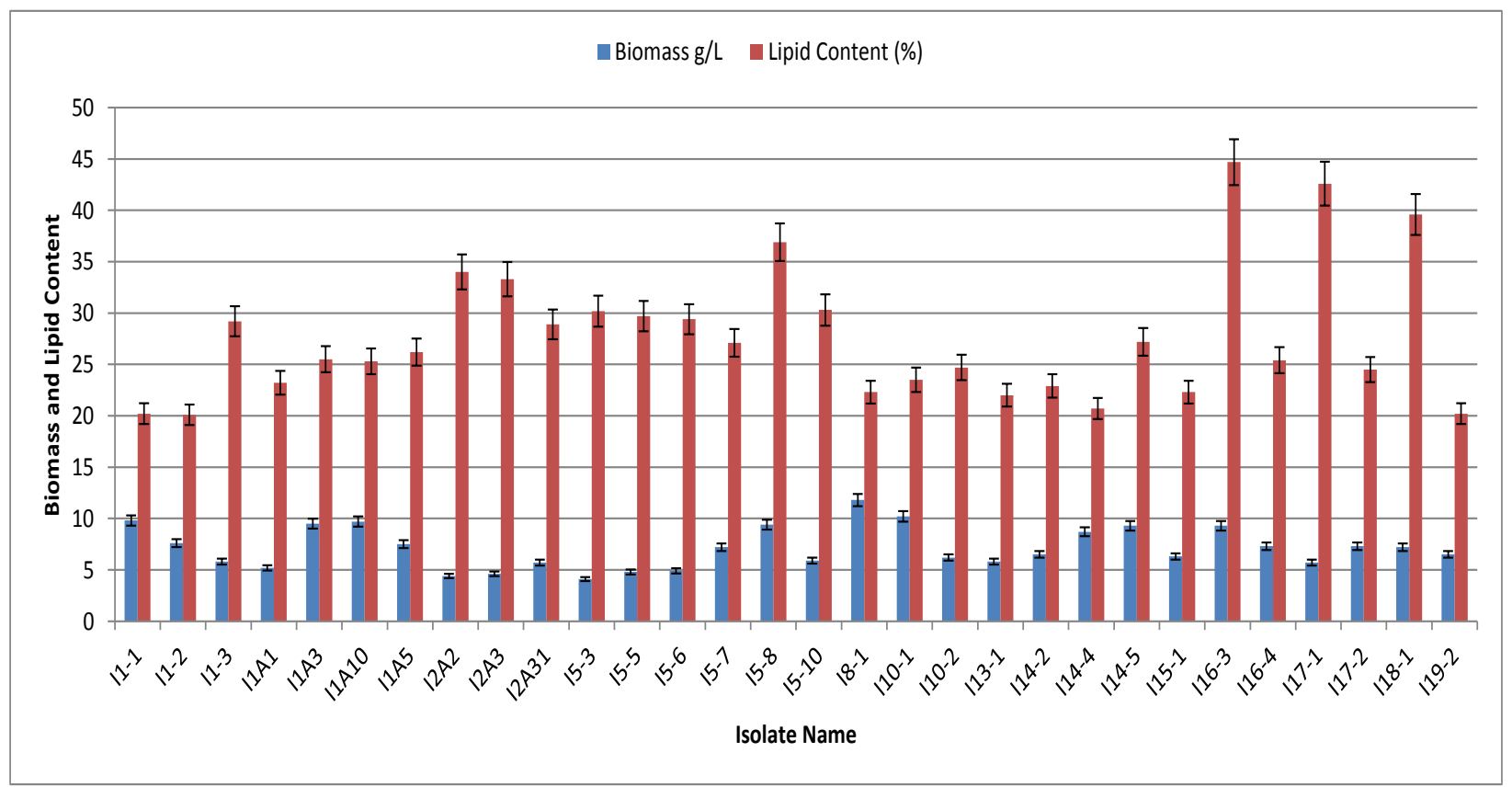


Fig.2 Characterization of isolated oleaginous fungi cultured in the starch containing medium

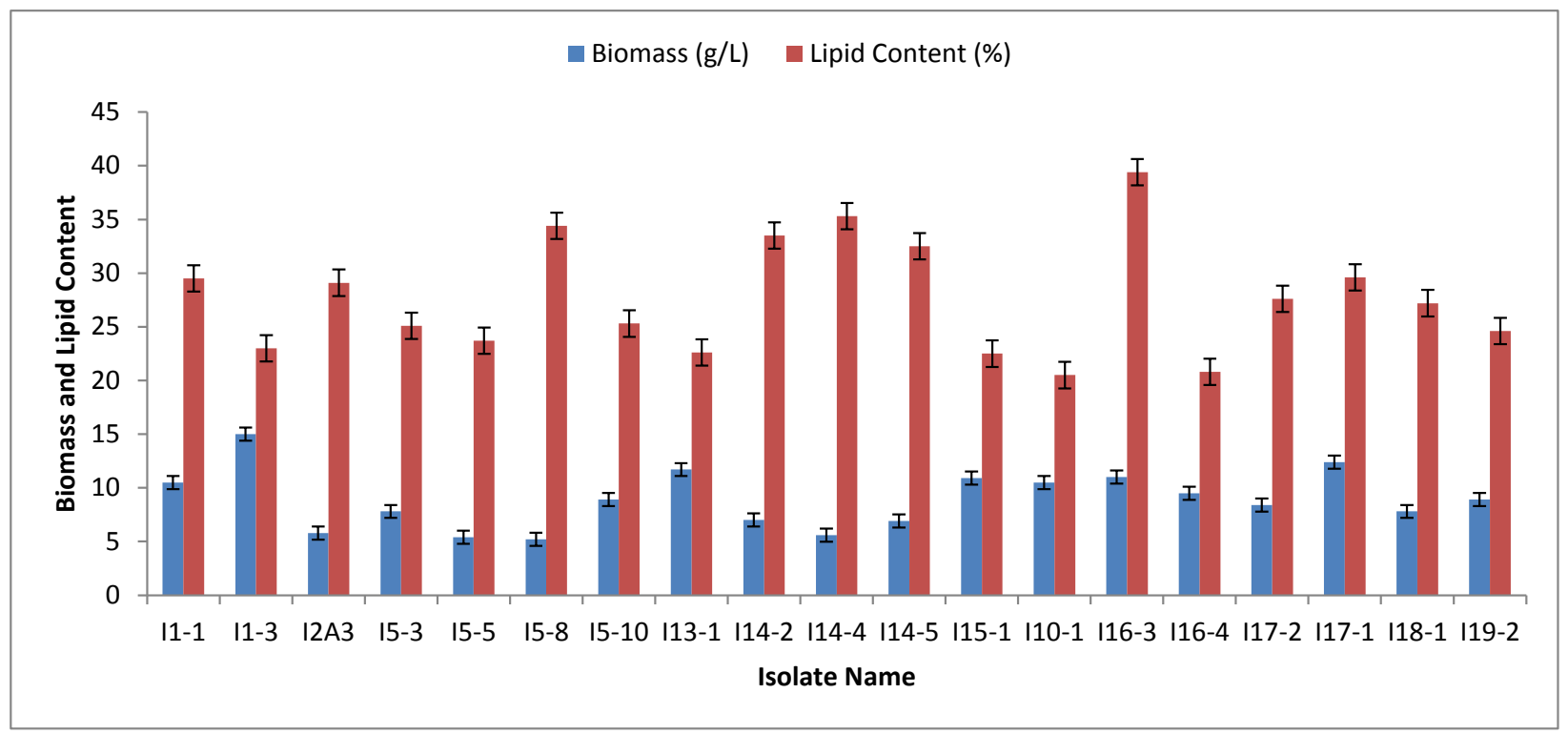

Table.1 Screening of oleaginous fungi with amylase secretion

\begin{tabular}{|c|c|c|c|}
\hline Isolate name & Width of the clearing zone(mm) & Width of the biomass(mm) & Hydrolytic capacity \\
\hline $\mathrm{I} 1-1$ & $10 \pm 2$ & $10 \pm 3$ & 1.00 \\
\hline $\mathrm{I} 1-3$ & $5 \pm 2$ & $8 \pm 1$ & 0.63 \\
\hline $\mathrm{I} 2 \mathrm{~A} 3$ & $3 \pm 1$ & $10 \pm 3$ & 0.30 \\
\hline $\mathrm{I} 5-3$ & $3 \pm 1$ & $5 \pm 4$ & 0.60 \\
\hline $\mathrm{I} 5-5$ & $2 \pm 2$ & $5 \pm 5$ & 0.40 \\
\hline $\mathrm{I} 5-8$ & $9 \pm 1$ & $5 \pm 2$ & 1.80 \\
\hline $\mathrm{I} 5-10$ & $5 \pm 2$ & $5 \pm 1$ & 1.00 \\
\hline $\mathrm{I} 13-1$ & $7 \pm 1$ & $4 \pm 3$ & 1.75 \\
\hline $\mathrm{I} 14-2$ & $4 \pm 3$ & $7 \pm 2$ & 0.57 \\
\hline $\mathrm{I} 14-4$ & $5 \pm 2$ & $10 \pm 1$ & 0.50 \\
\hline $\mathrm{I} 14-5$ & $2 \pm 3$ & $7 \pm 3$ & 0.29 \\
\hline $\mathrm{I} 15-1$ & $12 \pm 1$ & $10 \pm 2$ & 1.20 \\
\hline $\mathrm{I} 15-4$ & $3 \pm 2$ & $2 \pm 1$ & 1.50 \\
\hline $\mathrm{I} 16-3$ & $20 \pm 2$ & $10 \pm 3$ & 2.00 \\
\hline $\mathrm{I} 16-4$ & $3 \pm 3$ & $10 \pm 3$ & 0.30 \\
\hline $\mathrm{I} 16-5$ & $6 \pm 2$ & $4 \pm 4$ & 1.50 \\
\hline $\mathrm{I} 17-1$ & $9 \pm 3$ & $1 \pm 5$ & 9.00 \\
\hline $\mathrm{I} 18-1$ & $7 \pm 2$ & $8 \pm 2$ & 0.88 \\
\hline $\mathrm{I} 19-2$ & $3 \pm 1$ & $3 \pm 1$ & 1.00 \\
\hline
\end{tabular}

In this study, seven isolates (I1-1, I1-3, I13-1, I15-1, I16-3, I17-1 and I19-2) had $\mathrm{Y}_{\mathrm{L} / \mathrm{C}}$ values above $10 \mathrm{~g}$ lipids $/ 100 \mathrm{~g}$ of glucose consumed and a maximum value of $19.3 \mathrm{~g}$ lipids/100 $\mathrm{g}$ of glucose consumed was observed in the isolate I16-3 (Table 1). $\mathrm{Y}_{\mathrm{L} / \mathrm{C}}$ values of 14.9 and $15.2 \mathrm{~g}$ lipids $/ 100 \mathrm{~g}$ of glucose consumed were obtained when Mortierella isabelliana 
and Cunninghiamella echinulata were cultured on the medium containing 3\% starch. Much lower $\mathrm{Y}_{\mathrm{L} / \mathrm{C}}$ of $3.5 \mathrm{~g}$ lipids/100 $\mathrm{g}$ of starch consumed was obtained when Aspergillus oryzae was grown on $4 \%$ starch. These results suggest that Isolate I16-3 is a potential starch utilizing culture; this is probably because of its high amylase activity.

Amylase is the primary enzyme responsible for starch hydrolysis. It is reported that, when complex carbon sources are used for microbial lipid production, the capability of oleaginous fungi in secretion of amylase is critical to obtain high lipid yields (16). Hence, in this chapter, all 50 isolates were screened for amylase secretion on plates and the positive ones were tested with the lipid producing medium containing $3 \%$ starch. The results showed that, among the 50 isolates screened, 19 isolates were positive $(+\mathrm{ve})$ for amylase secretion with the width of the clearing zones ranging from 2 to $20 \mathrm{~mm}$ and the width of the biomass ranging from 3 to 40 $\mathrm{mm}$ (Table 1). The result shows that the isolates which were positive were all oleaginous. The isolate I16-3 achieving the highest lipid yield possessed the highest amylase activity with a $20 \mathrm{~mm}$ clearing zone in plates and $34 \mathrm{U} / \mathrm{mL}$ of amylase was secreted in the liquid medium (Table 1).

In order to use low-cost starchy substrates as raw materials for microbial lipid production, it is important to use oleaginous fungi with amylase secretion capability so as to reduce the lipid production cost. However, in the literature very few oleaginous microbes with amylase secretion capability for utilization of starchy wastes have been reported; they were Aspergillus oryzae, M. isabelliana ATHUM $2935(0.12 \mathrm{IU} / \mathrm{mL})$ and $C$. echinulata ATHUM $4411 \quad(0.19 \mathrm{IU} / \mathrm{mL})(16)$. Other studies on use of starch based wastes for microbial lipid production either utilize commercial amylase or followed an initial step of cultivating amylase positive cultures on starchy waste to hydrolyse starch and then employed oleaginous microorganisms on hydrolysate for lipid production. For instance, alpha amylase and gluco amylase were added to hydrolyze cassava starch for lipid production by micro algae Chlorella protothecoide (20-22). Li et al., (2010) used Streptomyces fibuligera amylase secreting culture to produce crude amylase, which was then added to cassava starch hydrolysate for lipid production by Rhodotorula mucilaginosa TJY15a. In the present study, 19 oleaginous fungi were observed to have amylase secretion, which can be useful for low-cost lipid production by using starchy wastes.

\section{Molecular identification of oleaginous fungi}

Sequencing of $18 \mathrm{~s}$ rDNA of the total 30 from fifty oleaginous isolates shows that they belonged to seven different genus: Trichoderma sp., Penicillium sp., Aspergillus sp., Mortierella sp., Zygomycetes sp., Acremonium sp. and Umbiliopsis sp. (Fig. 2). Among the seven genera, 13 isolates showed $99 \%$ similarity with already reported sequences of reference strains identified by BLAST analysis and the sequences were submitted to the NCBI gene bank (Acc. No: JF895924，JF895925，JF895926，JF895927, JF895928，JF895929, JF895930, JF912414, JF912415，JF912416，JF912417，JF912418 and JF912419). Out of the 30 isolates, seven, ten, seven and three belongs to Trichoderma sp., Penicillium sp., Aspergillus sp. and Zygomycetes sp., respectively; one each of Mortierella sp., Acremonium sp. and Umbliopsis sp.was identified (Table 1). Most of the studies in the literature related to oleaginous fungi used the Mucorales order; very few, to our best knowledge, only one genus Aspergillus which is non mucaraceous fungi have been used for lipid production. In addition, oleaginous fungi belonging to the Mucorales order are always used for 
production of lipids with special long- chain poly unsaturated fatty Acids (PUFA), such as gamma linolenic acid (GLA) and arachidonic acid (AA). These fatty acids have nutritional importance. The present study explored fungi which were capable of producing lipids and did not belong to the Mucorales order. Non mucarales fungi are attractive alternative fungi for microbial lipid production; Aspergillus a known oleaginous fungus belongs to the Deutromycetes order, Tricoderma belongs to the Hypocreales order, and Penicillum belongs to the Eurotiales order.

Furthermore, their amylase secretion could be an additional advantage when using starch wastes for low-cost lipid production. Acremonium sp. is well known for hydrolysis of lignocellulosic materials (23), while in this study, it is found that Aceremonium sp. (I181) possessed starch utilizing capability and oleaginous nature. This is reported in the first time to the best of our knowledge. Therefore, this culture might be used for simultaneous saccharification and fermentation (SSF) of lignocellulosic materials for lipid production.

This could be an attractive option for producing the second generation biofuels. When the microbial oil is used for biodiesel applications, European standards (EN14214 and 14213) regulate that the PUFA content in the microbial oil should not be more than $12 \%$. Our study has explored non mucaraceous oleaginous fungi whose PUFA contents presumably would not exceed the limit.

This paper dealt with fungi in lipid production with the media containing glucose and starch was studied. Many non mucaraceous oleaginous fungi with amylase secretion capability were reported, which could be used for low cost lipid production using starchy waste materials as carbon substrates.

\section{References}

1. Ratledge C. Fatty acid biosynthesis in microorganisms being used for Single Cell Oil production. Biochimie. 2004; 86(11): 807-15.

2. Shi S, Valle-Rodriguez JO, Siewers V, Nielsen J. Prospects for microbial biodiesel production. Biotechnol $\mathrm{J}$. 2011; 6(3): 277-85.

3. Li Q, Du W, Liu D. Perspectives of microbial oils for biodiesel production. Applied Microbiology and Biotechnology. 2008; 80(5): 749-56.

4. Li P, Miao X, Li R, Zhong J. In situ biodiesel production from fast-growing and high oil content Chlorella pyrenoidosa in rice straw hydrolysate. $\mathrm{J}$ Biomed Biotechnol. 2011; 141-207.

5. Meng X, Yang JM, Xu X, Zhang L, Nie QJ, Xian M. Biodiesel production from oleaginous microorganisms. Renewable Energy. 2009; 34(1): 1-5.

6. Coradini A, Anschau A, Vidotti A, Reis É, da Cunha Abreu Xavier M, Coelho $\mathrm{R}$, et al., Microorganism for Bioconversion of Sugar Hydrolysates into Lipids. In: Kamm B, editor. Microorganisms in Biorefineries: Springer Berlin Heidelberg; 2015. p. 51-78.

7. Ratledge C, Wynn JP. The biochemistry and molecular biology of lipid accumulation in oleaginous microorganisms. Adv Appl Microbiol. 2002; 51: 1-51.

8. Shene C, Leyton A, Esparza Y, Flores L, Quilodran B, Hinzpeter I, et al., Microbial Oils and Fatty Acids: Effect of Carbon Source on Docosahexaenoic Acid (C22:6 N-3, Dha) Production by Thraustochytrid Strains. Journal of Soil Science and Plant Nutrition. 2010; 10(3): 207-16.

9. Sakuradani E, Shimizu S. Single cell oil production by Mortierella alpina. J 
Biotechnol. 2009 Oct 12;144(1):31-6.

10. Ratledge C. Single cell oils--have they a biotechnological future? Trends Biotechnol. 1993; 11(7): 278-84.

11. Patnayak S, Sree A. Screening of bacterial associates of marine sponges for single cell oil and PUFA. Lett Appl Microbiol. 2005; 40(5): 358-63.

12. Kendrick A, Ratledge C. Lipids of selected molds grown for production of n-3 and n-6 polyunsaturated fatty acids. Lipids. 1992; 27(1): 15-20.

13. Ratledge C. Tailor-Made Oils and Fats Possibilities for Microbial Oils. Revue Francaise Des Corps Gras. 1992; 39(1112): 325-32.

14. Vicente G, Martinez M, Aracil J. Integrated biodiesel production: a comparison of different homogeneous catalysts systems. Bioresour Technol. 2004; 92(3): 297-305.

15. Sims REH, Mabee W, Saddler JN, Taylor M. An overview of second generation biofuel technologies. Bioresource Technology. 2010; 101(6): 1570-80.

16. Papanikolaou S, Galiotou-Panayotou M, Fakas S, Komaitis M, Aggelis G. Lipid production by oleaginous Mucorales cultivated on renewable carbon sources. European Journal of Lipid Science and Technology. 2007; 109(11): 1060-70.

17. Zikou E, Chatzifragkou A, Koutinas AA, Papanikolaou S. Evaluating glucose and xylose as cosubstrates for lipid accumulation and $\gamma$-linolenic acid biosynthesis of Thamnidium elegans.
Journal of Applied Microbiology. 2013.

18. Kavadia A, Komaitis M, Chevalot I, Blanchard F, Marc I, Aggelis G. Lipid and gamma-linolenic acid accumulation in strains of zygomycetes growing on glucose. Journal of the American Oil Chemists Society. 2001; 78(4): 341-6.

19. Ahmed SU, Singh SK, Pandey A, Kanjilal S, Prasad RBN. Effects of various process parameters on the production of gamma-linolenic acid in submerged fermentation. Food Technology and Biotechnology. 2006; 44(2): 283-7.

20. Wei Z, Xu C, Li B. Application of waste eggshell as low-cost solid catalyst for biodiesel production. Bioresour Technol. 2009; 100(11): 2883-5.

21. Lu Y, Ding Y, Wu Q. Simultaneous saccharification of cassava starch and fermentation of algae for biodiesel production. Journal of Applied Phycology. 2011; 23(1): 115-21.

22. Lu Y, Zhai Y, Liu M, Wu Q. Biodiesel production from algal oil using cassava (Manihot esculenta Crantz) as feedstock. Journal of Applied Phycology. 2010; 22(5): 573-8.

23. Beopoulos A, Cescut J, Haddouche R, Uribelarrea J-L, Molina-Jouve C, Nicaud J-M. Yarrowia lipolytica as a model for bio-oil production. Progress in Lipid Research. doi: 10.1016/j.plipres.2009.08.005. 2009; 48(6): 375-87.

\section{How to cite this article:}

Iniya Kumar Muniraj, Liwen Xiao, Zhenhu $\mathrm{Hu}$ and Xinmin Zhan. 2017. Screening and Characterization of Oleaginous Fungi from Irish Soil for Growth under Low Carbon Substrates. Int.J.Curr.Microbiol.App.Sci. 6(12): 772-781. doi: https://doi.org/10.20546/ijcmas.2017.612.082 